\title{
Observatório de Jornalismo Ambiental: um projeto de extensão em prol da cidadania
}

\section{Eloisa Beling Loose}

Universidade Federal do Rio Grande do Sul, Programa de Pós-Graduação em Comunicação, Porto Alegre, RS, Brasil

ORCID: https://orcid.org/0000-0002-4755-3046

\section{Matheus Cervo}

Universidade Federal do Rio Grande do Sul, Programa de Pós-Graduação em Comunicação, Porto Alegre, RS, Brasil

ORCID: https://orcid.org/0000-0002-6913-802X

\section{Mathias Lengert}

Universidade Federal do Rio Grande do Sul, Programa de Pós-Graduação em Comunicação, Porto Alegre, RS, Brasil

ORCID: https://orcid.org/0000-0002-7472-8788

\section{Resumo}

Os observatórios de mídia podem ser vistos como atores políticos que apresentam resistências, com o papel social de apontar aos públicos outras formas de ver os acontecimentos. A partir desse entendimento, o Grupo de Pesquisa em Jornalismo Ambiental (GPJA), da Universidade Federal do Rio Grande do Sul (UFRGS), percebeu que a criação de um observatório dedicado à cobertura de meio ambiente poderia não só extrapolar os muros da universidade, levando as reflexões acadêmicas para outros espaços e praticando a extensão a partir de atividades de ensino e pesquisa, como também qualificar o debate ambiental no contexto brasileiro, fomentando o exercício efetivo da cidadania planetária. Este texto, de caráter analítico-exploratório, apresenta a iniciativa e discute os desafios associados à crítica jornalística ambiental. Ressaltam-se, como considerações finais, os limites identificados na produção empírica, decorrentes de uma lógica jornalística nem sempre associada à cidadania, e na própria manutenção dos projetos de extensão nas universidades, fatores que restringem o potencial pedagógico dos observatórios e, nesse caso, do debate sobre jornalismo ambiental.

\section{Palavras-chave}

Observatório de Mídia; Jornalismo Ambiental; Crítica jornalística; Extensão; Jornalismo e Cidadania 


\section{Introdução}

Dentre os pressupostos do Jornalismo Ambiental (doravante JA), fica evidente que há um propósito que vai além de informar, já que pretende mobilizar, sensibilizar, transformar a percepção de mundo em relação ao meio ambiente. Dito de outra forma, acredita-se que a informação qualificada sobre o meio ambiente é o início de um processo que pode gerar ações mais afinadas com a sustentabilidade da vida, expressão usada por Leff (2016), para dar conta daquilo que os povos indígenas chamam de "viver bem" ou "buen vivir" e outros termos que refletem a diversidade dos modos de existência dos povos da Terra.

O Grupo de Pesquisa Jornalismo Ambiental (GPJA), envolvido em ações de pesquisa, ensino e extensão orientadas para uma melhor cobertura do tema desde 2008, criou, em 2019, um projeto de extensão voltado pelas premissas do JA e das funções atreladas aos observatórios. Até hoje, não há no Brasil outro observatório especializado na cobertura ambiental (RENOI, 2021). A proposta é publicar sistematicamente análises a respeito de como a imprensa tem retratado as questões da área, a partir de notícias, reportagens ou coberturas específicas, sinalizando aspectos positivos e caminhos para alterar o que, de alguma maneira, reduz ou descontextualiza a problemática ambiental.

O Observatório de Jornalismo Ambiental (OJA) analisa tanto a cobertura de meio ambiente quanto produtos alinhados com os pressupostos do JA. A distinção é importante porque o que caracteriza o fazer jornalístico atravessado pela preocupação ambiental não é encontrado em todos os produtos com foco nessa temática. Mais do que uma especialização, o JA compreende que seu trabalho pode gerar transformações. Gavirati (2013, p. 224, tradução nossa) aponta que "No caso do jornalismo ambiental, trata-se de estimular a formação de uma consciência ecológica, como uma extensão da responsabilidade ou da ética profissional"1. Ao mesmo tempo, ao analisar a cobertura de meio ambiente que não considere essa perspectiva (mais abundante), é possível colaborar com a ampliação do debate jornalístico e também ambiental.

É importante mencionar que a ideia da criação deste dispositivo crítico surge no fim de 2018, quando a candidatura ao Governo Federal, eleita em outubro, já demonstrava em campanha descaso com o cuidado do meio ambiente. Junto a isso, houve o aumento da percepção de que as muitas crises, associadas à desconexão do homem com a natureza,

\footnotetext{
1 No original: "En el caso del periodismo ambiental, se trata de estimular la formación de una conciencia ecológica, como una extensión de la responsabilidad o la ética profesionales." (GAVIRATI, 2013, p. 224).
} 
tornavam-se cada vez mais presentes no nosso cotidiano, chamando a atenção da mídia. 0 acompanhamento de mais de uma década dos assuntos ambientais na imprensa brasileira pelo GPJA permite depreender que tais temáticas, antes periféricas, tornaram-se frequentes, devido ao agravamento das mudanças climáticas (STENGERS, 2015), desmonte das políticas públicas ambientais (BRUM, 2019), intensificação do neoextrativismo (SWAMPA, 2019), dentre outros fatores que culminaram em uma série de acontecimentos que já não podem ser ignorados pelo jornalismo.

Neste texto, tensionamos os objetivos dos observatórios de mídia e os pressupostos do JA, a partir da experiência do OJA, e refletimos sobre os desafios de tratar temas diferentes, mas que emergem de um problema comum: a desconexão da humanidade com o lugar que habita e a hegemonia de uma racionalidade econômica exploratória. Entendemos, assim como Motta (2008), que os observatórios podem ser vistos como atores que demarcam posição frente à indústria cultural e informativa hegemônica, já que se guiam pela consciência do papel social da imprensa nas democracias.

\section{Para que servem os observatórios de mídia?}

Os observatórios de mídia são, fundamentalmente, experiências que buscam assegurar a estabilidade democrática e a garantia da cidadania, exercendo-se em um duplo movimento de crítica e diálogo sobre as práticas midiáticas, e permeando debates acerca de sua responsabilidade social de comunicação inclusiva, direito à informação e liberdade de expressão (TÉLLEZ, 2011). Ao mapear a literatura científica e a atuação diversificada dos observatórios, Moreira (2013, p. 81) os define como iniciativas de monitoramento de “[...] conteúdos, políticas e/ou sistemas de comunicação, buscando contribuir para o aperfeiçoamento destes", de modo que atuam como um contrapeso democrático a excessos da mídia.

A despeito da diversidade de categorizações reconhecidas sobre os observatórios de mídia, Albornoz e Herschmann (2006) concebem dois conjuntos com funcionamentos distintos: o observatório fiscal, que intenta monitorar os meios de comunicação e, assim, articular a participação cidadã, e o observatório think tank, que busca refletir e intervir nas políticas públicas de comunicação. Em contrapartida, Cunha (2011) entende que a classificação dos autores é insuficiente, propondo uma categoria de ação (que agrega as práticas de monitoramento, produção de notícias, capacitação de profissionais e do público e 
consultoria) e uma de reflexão (que pode promover práticas de ativismo, formulação de políticas públicas de comunicação, fórum de discussão, laboratórios de pesquisas e análises sobre a documentação midiática).

Os esforços de classificação desses autores mostram a dificuldade de uma definição uniforme e específica dos observatórios de mídia. De forma genérica, no entanto, é possível afirmar que essas iniciativas se caracterizam por uma miríade de práticas de acompanhamento da atuação midiática, de modo a expressar críticas e tensionar os produtos. Desta forma, distinguem-se por desenvolverem contribuições de caráter propositivo, como a defesa de direitos humanos, a participação plural nos processos midiáticos, a autonomia crítica aos meios de comunicação, etc. (MOREIRA, 2013). Tal postura propositiva está no cerne do 0JA, que, como veremos adiante, sugere formas outras de cobrir a pauta ambiental, fundamentado nas pesquisas realizadas há mais de uma década pelo GPJA.

A proposta de observatórios estabelecerem uma interlocução entre a mídia e a sociedade baseia-se em três atravessamentos: a cidadania, a democracia e a crítica de mídia. O exercício da cidadania pressupõe um projeto de sociabilidade em construção íntegra do indivíduo com a coletividade. A cidadania figura de maneira descontínua na comunicação midiática, de modo que, em contrapartida, os observatórios se caracterizam como dispositivos estratégicos dos cidadãos em resposta às restrições e incipiências de direitos, suportes de reivindicação mais participativas e críticas, que deem conta da responsabilidade social que as mídias carecem (TÉLLEZ, 2011).

Os observatórios de mídia cristalizam a cidadania ao promover um trabalho pedagógico. Para Téllez (2011), trata-se de uma mobilização que parte de universidades e grupos de pesquisa, respaldando experiências avaliativas das práticas midiáticas e suas implicações ao cidadão consumidor. Assim são os esforços do OJA, que convergem na tarefa de sensibilizar o público para a importância do meio ambiente e uma concepção de jornalismo compromissada com a pluralidade de vozes, isto é, atenta à (des)valorização da cidadania nas práticas jornalísticas. Esse movimento crítico e pedagógico materializa demandas por direito à comunicação ambiental, promovendo o cuidado com o meio ambiente, do qual somos parte.

A solidificação da democracia é um processo análogo à garantia da cidadania. A defesa de direitos plenos aos indivíduos indica um efetivo regime social de liberdade e igualdade. Nesse entremeio, a mídia desempenha um exercício de resposta aos desejos, interesses e requisições de atores sociais engajados em âmbito democrático (TÉLLEZ, 2011). Esse cenário 
é imperativo para a instituição de instrumentos de crítica dos processos midiáticos, indicam Rebouças e Cunha (2010) em um estudo sobre 77 observatórios de mídia de 23 países, no qual verificaram uma intrínseca relação dessas iniciativas com os regimes democráticos. A atuação dos observatórios direciona um projeto de reflexão e participação política ante os meios de comunicação, de modo a "[...] contribuir para uma modificação dos valores em uma direção mais democrática em prol do interesse público" (REBOUÇAS; CUNHA, 2010, p. 92) e, assim, estabelecer um engajamento do público com a democratização da mídia e da sociedade.

A crítica midiática decorre dessa relação estreita da democracia e da cidadania. Desempenha uma avaliação do funcionamento da imprensa e incentiva uma pedagogia crítica do público em relação ao consumo das informações e dos próprios meios de comunicação. Esse exercício cristaliza uma demanda por parâmetros mais exitosos na produção do conteúdo midiático, em especial, do jornalismo. A exigência por maior qualidade na atividade jornalística torna a crítica de mídia, para Rocha Neto et al. (2015), uma prática ativista, pois essa exerce um monitoramento em diálogo com instâncias e atores diversos da sociedade, de modo a valorizar as responsabilidades éticas da comunicação midiática, especialmente a pluralidade de vozes e a diversidade de perspectivas e narrativas.

Movidas pelos questionamentos "Quem pode fazer a crítica da crítica? O que pode fazer a crítica acadêmica?", Soares e Silva (2016, p. 19) indicam a crítica de mídia como lugar de desconstrução de discursos estabelecidos, em que ponderações e discordâncias são acionadas nos meios de comunicação. Nesse sentido, cabe à crítica "[...] evidenciar pontos de vista dissonantes sobre as mídias e problematizar formatos considerados hegemônicos" (SOARES; SILVA, 2016, p. 19), promovendo um exercício crítico polifônico, dinâmico e heterogêneo. Dado que o jornalismo engloba uma rede de relações, compartilhando seus valores com públicos e audiências, cabe a todos os atores interessados realizar e aprimorar a crítica (SILVA; SOARES, 2013). Portanto, a responsabilidade por uma competência crítica é plural, sucedendo em discussões acadêmicas, avaliações de especialistas e na ampliação do debate do público.

Assim, a atividade desses observatórios contribui para o amadurecimento da crítica midiática; além disso, o monitoramento da produção da imprensa incentiva a atenção do jornalismo aos seus deveres éticos, como a exatidão da informação e o equilíbrio das diferentes perspectivas e fontes. Constituem-se em instrumentos de crítica que asseguram a 
complexificação de discussões de interesse sobre a atuação e a credibilidade da imprensa (ROCHA NETO et al., 2015).

As questões levantadas aqui apontam para três aspectos fundamentais que compõem os observatórios de mídia. 0 primeiro deles refere-se ao exercício da cidadania, promovido pela reivindicação de direitos e o trabalho pedagógico; o segundo expressa a indispensabilidade da democracia para o engajamento do público com o debate; e o terceiro indica a crítica como ferramenta de aprimoramento dos processos midiáticos. Os observatórios de mídia, definidos a partir desses traços, são dispositivos críticos e dialógicos que buscam enredar a mídia como espaço plural, aberto à alteridade.

Diante de sua atuação crítica, essas iniciativas instituem olhares e enfoques diversos da realidade social, propondo outras formas de construir os acontecimentos. A sua intencionalidade pedagógica indica que os observatórios possuem o propósito de educar o público à autonomia crítica e promover uma cultura de interação da sociedade com a mídia (TÉLLEZ, 2011). Trata-se de objetivar uma participação ativa do público, reconhecendo que as mudanças propostas pelo observatório exigem o comprometimento da audiência (DAMAS; CHRISTOFOLETTI, 2006).

Esse cenário dialógico, proposto por esses dispositivos, é impulsionado pelas ferramentas digitais, que garantem maior interação com o público e acessibilidade das atividades a baixos custos (DAMAS; CHRISTOFOLETTI, 2006). Para Téllez (2011), os observatórios ocupam posições estratégicas em ambiência digital, possibilitando a divulgação e a interação contínua com os leitores.

As interlocuções dos observatórios de mídia surgem de demandas amplas da sociedade, atuando em múltiplas frentes. Ao analisar as iniciativas brasileiras, Moreira (2013) constata que a diversidade é sua condição primeira, porque tais entidades possuem formatos, propósitos e atuações heterogêneas. A versatilidade dos observatórios midiáticos indica que essas experiências encontraram o lugar da crítica em diversos produtos, processos e interfaces, de modo que, para Damas e Christofoletti (2006), os observatórios respondem à criatividade e aos anseios dos seus responsáveis. Essas iniciativas, portanto, buscam democratizar a mídia, expandindo uma cultura de crítica midiática, outrora restrita à academia e ao círculo de especialistas. Para os autores, os observatórios vinculados às universidades fortalecem as condutas éticas de jornalistas e possuem a função de acompanhar os espaços midiáticos, afinal, “[...] é papel da universidade não apenas fazer a crítica de mídia, mas também estudar a crítica" (SOARES; SILVA, 2016, p. 20). 
Os integrantes do OJA são pesquisadores atentos aos estudos da Comunicação e do Meio Ambiente, de modo que os processos de investigação estejam em constante troca com as análises dos produtos que circulam na sociedade. Alinhados com a defesa da democracia e da cidadania, integramos o cuidado com a vida, no seu sentido amplo. A sustentabilidade da vida (LEFF, 2016) corre riscos, diz respeito à sobrevivência da humanidade e não pode seguir sendo minimizada ou ignorada pelo jornalismo.

\section{Entendimentos do que é Jornalismo Ambiental}

Embora o jornalismo dedicado ao meio ambiente tenha derivado do jornalismo científico (BELMONTE, 2017), hoje se percebe a atividade como muito mais transversal do que a especialização da qual se originou. A cobertura ambiental necessita fazer uso dos conhecimentos que abarcam o campo científico, traduzindo termos técnicos e permitindo uma correta popularização da ciência. Todavia, o campo ambiental é interdisciplinar e engloba muitas esferas, revelando questões outras, como a do engajamento e do comprometimento com a pauta, por exemplo. Como afirma Frome, é preciso estar atento aos dados científicos e técnicos, mas é necessário “[...] um sentimento, uma filosofia, amor à terra, amor à vida"(FROME, 2008, p. 86).

Bueno (2007), um dos pesquisadores brasileiros pioneiros nessa área, aponta que o JA apresenta três funções: a informativa, a educativa e a política (atrelada ao exercício da cidadania). Tais propósitos se entrelaçam e podem estar mais ou menos evidentes nos produtos jornalísticos, mas demonstram o intuito de avançar sobre a tradicional (muitos diriam obsoleta) ideia de que cabe ao jornalista apenas revelar os fatos (como se houvesse alguma possibilidade de não posicionamento durante qualquer ato comunicativo). A defesa da preservação do planeta, do qual fazemos parte e não somos meros visitantes, ainda gera certo desconforto diante das teorias jornalísticas que pregam a imparcialidade ou entendem a objetividade como resultado alcançável.

Por outro lado, cada vez mais, eclodem tipos de jornalismo que reivindicam a necessidade de observarmos a subjetividade (MORAES, 2019) e que entendem, como já declarou o jornalista André Trigueiro em diferentes oportunidades, a necessidade de estar comprometido com a sustentabilidade da vida (LEFF, 2016), assim como se está com o combate à corrupção e ao autoritarismo ou com a defesa dos direitos humanos. 0 Código de Ética do Jornalistas Brasileiros evidencia que a profissão é compromissada com algumas 
pautas: "Art. 60 É dever do jornalista: I - opor-se ao arbítrio, ao autoritarismo e à opressão, bem como defender os princípios expressos na Declaração Universal dos Direitos Humanos" (FENAJ, 2007).

Dado que, eticamente, os profissionais são incumbidos da defesa dos direitos humanos, por que o direito a um ambiente saudável, preservado e em equilíbrio deveria ser visto como militância ou algo de valor menor? Por que o entendimento não é o mesmo quando falamos da defesa ambiental?

Na apresentação do livro Green Ink, de Michael Frome, Sá Correia (2008) indica que o jornalismo ambiental pode ser considerado um jornalismo de advocacy, defendendo uma consciência de preservação das relações ecossistêmicas entre a natureza e a humanidade, em oposição a interesses exclusivamente econômicos. Girardi (2018), que introduziu a alfabetização ambiental na prática, pesquisa e ensino do jornalismo e se tornou uma das referências da área no Brasil, sempre sublinhou que:

O Jornalismo exerce um papel social fundamental na informação e formação do cidadão, disponibilizando a este ferramentas para atuar na defesa de seus interesses e também dos interesses da sociedade. Nesses tempos tão conturbados, em que a ameaça de danos ao meio ambiente é constante, o Jornalismo Ambiental é necessário para imprimir um olhar cuidadoso e comprometido com a defesa da vida em todas suas dimensões. (GIRARDI, 2018, p. 21).

Logo, os objetivos do OJA permitem que o jornalismo ambiental se dissemine, que a comunidade possa entender o modus operandi do fazer jornalístico e possa perceber que há várias escolhas intrínsecas ao processo de produção de conteúdo jornalístico. Mais do que relatar fatos ambientais (o que podemos chamar de jornalismo de/sobre meio ambiente), o JA pressupõe envolvimento e uma visão sistêmica sobre os acontecimentos diários. Os métodos investigativos e demais técnicas jornalísticas são mobilizados para evidenciar as conexões entre causas e consequências, entre processos interligados que, por interesse de poucos, são apresentados de forma fragmentada e descontextualizada.

Recorda-se que a contextualização do acontecimento pelo jornalismo é redefinida, por sua vez, a partir da experiência tecnológica. Além disso, o ambiente midiático digital reorganiza as interações do jornalismo com outros atores sociais, tais como os leitores e as fontes de informação. A maior interatividade torna os conteúdos multifacetados, abrange uma pluralidade de perspectivas, evitando, deste modo, que os temas sejam 
compartimentalizados. Com as transformações do jornalismo no século XXI, a informação se descentraliza, de modo que iniciativas de jornalismo alternativo ganhem força. Por fim, a interatividade fomenta o "[...] diálogo potente entre jornalistas e públicos na construção de conhecimentos mais problematizadores e transformadores da realidade cotidiana" (FREIREBEZERRA, 2020, p. 101), interlocuções essas que contribuem para a consciência crítica e cidadã de temas pertinentes à sociedade, tal como a questão ambiental.

Retomando a compreensão do jornalismo ambiental, Gavirati (2013) o diferencia em duas formas: um JA empírico, encontrado nas páginas dos jornais, na televisão, no rádio e nos sites de internet, e um conceitual, associado a uma expectativa, a como o jornalismo deveria cobrir o meio ambiente. $\mathrm{Ou}$, com outras palavras, uma cobertura de meio ambiente praticada a partir de uma série de limitações, que vão desde a escassez de tempo e falta de formação profissional orientada para a perspectiva ambiental até a precarização das redações, e outra guiada pelo propósito ambientalista (porém, nem sempre de fácil execução na prática).

Outra forma lembrada por Gavirati (2013) está associada ao espaço ofertado ao tema dentro do jornalismo. 0 jornalismo ambiental pode ser visto como uma especialização profissional, promovido por veículos segmentados ou com editorias específicas, ou como algo mais amplo - posição sustentada pelos pesquisadores do GPJA -, que pode ser compreendida como uma oportunidade de renovação do jornalismo como um todo, já que os profissionais incorporariam as lentes ambientais e passariam a trabalhar o tema na cobertura de diferentes assuntos. A transversalidade, então, se tornaria realidade.

Apesar dos desafios que se colocam entre a teoria e a prática, acredita-se que é viável realizar com profissionalismo o dever jornalístico pensando na preservação da vida, que é fato de interesse público porque diz respeito a toda humanidade. $\mathrm{O}$ foco é o cuidado do nosso habitat e do bem-estar humano e das demais espécies. A proposta é questionar as decisões tomadas que consideram apenas alguns aspectos do todo, ignorando os rastros de destruição que as ações humanas deixam. Conforme diz Stengers (2015), as palavras têm poder, e as seleções de fatos para criar formas de apresentação das histórias contadas pelos jornalistas (que geralmente desfrutam de legitimidade e grande alcance) interferem na forma como se dá (ou não) o debate público e as tomadas de decisão.

Em nome da insustentável ideia de que é possível crescer de forma ilimitada ou, ainda, de que é preciso sacrificar a natureza para diminuir os problemas sociais, os discursos políticos hegemônicos calcados na racionalidade econômica continuam sendo propagados pela imprensa sem contrapontos. 0 jornalismo raso (ou mau jornalismo), também chamado 
de declaratório, apenas reproduz as falas de fontes oficiais, amplificando-as sem ouvir atores que ofertem contrapontos. Swampa (2019), ao retratar como se dá o processo de neoextrativismo na América Latina, lembra que a linguagem empregada tende a invisibilizar as populações locais, ao mesmo tempo que os modelos de exploração são postos como a única alternativa:

[...] a afirmação de que existem regiões marcadas historicamente pela pobreza e pela vulnerabilidade social, com baixa densidade populacional, que contam com grandes extensões de territórios "improdutivos", facilita a instalação de um discurso eficientista e excludente em nome das dinâmicas globais do capital. (SWAMPA, 2019, p. 58).

O JA que endossamos assume a perspectiva ambiental e se compromete a retratar quadros mais plurais e alargados, com diferentes visões que podem revelar as contradições e conflitos existentes em cada escolha. Na contramão dos interesses hegemônicos, que historicamente usaram a natureza como recurso econômico, o JA tenta ampliar o entendimento dos fatos e contribuir com uma visão mais complexa dos fenômenos. Para isso, abriga aqueles que fazem resistência aos projetos dominantes, partindo do pressuposto de que a natureza é um bem comum e, portanto, deve ser protegida não apenas para nós, mas para todos os seres e futuras gerações.

Frome (2008, p. 263) pontua que “[...] o jornalismo ambiental ajuda a visionar e moldar uma sociedade melhor e uma democracia melhor", pois é preciso informação qualificada para exercer de forma responsável a cidadania. Bueno (2007) e Girardi (2018) também seguem essa linha, entendendo que a comunicação ambiental dá subsídios para tomadas de decisão mais acertadas.

Diante disso, o OJA se coloca como um dispositivo crítico, que busca promover a reflexão e reação nas práticas jornalísticas direcionadas ao meio ambiente, mas, também, estabelecer diálogo com os públicos sobre o que não está sendo dito, como está sendo apresentado ou como poderia ser abordado de outras formas. Não significa apenas esmiuçar o processo de fabricação da notícia ou destacar os problemas. É uma tentativa de formar cidadãos mais atentos e participativos no modo de se relacionar com o ambiente, de levantar inquietações e problematizar o próprio modo como percebemos a natureza. Um desafio enorme e urgente. 


\section{O OJA enquanto projeto de extensão e exemplos de suas atividades}

Nesta seção, apresentamos com mais detalhes o OJA enquanto projeto de extensão da Universidade Federal do Rio Grande do Sul (UFRGS) para, posteriormente, apontarmos algumas críticas que foram realizadas durante a existência desse observatório. É importante relembrar que esse projeto foi criado e é mantido pelo GPJA, que é um grupo de pesquisa coordenado pela professora Dra. Ilza Maria Tourinho Girardi e registrado no Conselho Nacional de Desenvolvimento Científico e Tecnológico (CNPq) desde 2008. A professora iniciou o seu percurso de pesquisa na interface entre Comunicação e Meio Ambiente no seu mestrado defendido em 1988 e, desde então, orientou muitos pesquisadores interessados na temática e deu continuidade a outras pesquisas em grupo.

Com isso, o projeto surgiu em 2019 como forma de contribuir para o tripé ensino, pesquisa e extensão que sustenta as instituições de ensino superior. A Pró-Reitoria de Extensão da UFRGS define a atividade extensionista como um “[...] processo educativo, cultural e científico que articula o ensino e a pesquisa de forma indissociável e viabiliza a relação transformadora entre universidade e sociedade" (PROREXT, 2021). Dessa forma, esse tipo de atuação universitária constrói ciclos de conhecimento entre pesquisadores que fazem parte da instituição e diversos atores da sociedade, o que está intimamente ligado com a ideia de circuito recursivo de Edgar Morin e seus colaboradores (MORIN; CIURANA; MOTTA, 2003). Ao invés de estimular apenas uma produção de conhecimento de forma retroativa - ou seja, através do diálogo dos próprios pesquisadores consigo mesmos -, a construção de saberes se forma pela recursividade, já que ela necessariamente se alimenta da interação para com fontes externas.

Não é trivial notar que, há pouco tempo, foi publicado o primeiro censo da Rede Nacional de Observatórios da Imprensa (RENOI) que mapeou os grupos que prioritariamente trabalham com crítica de mídia e monitoramento de coberturas jornalísticas no momento presente. Nesse documento, constatou-se a existência de 25 observatórios, sendo que 24 foram criados no século XXI, 23 são pertencentes a alguma universidade pública e dois são oriundos de faculdades privadas. Assim sendo, é possível perceber a conexão inerente dos projetos de extensão com as atividades de monitoramento dos diversos tipos de jornalismos no Brasil, principalmente pela via dos pesquisadores que fazem parte das redes públicas de ensino superior (RENOI, 2021). 
Nesse mesmo censo, é possível verificar que o OJA foi o primeiro observatório a ter como foco a questão ambiental. Recordamos que o OJA se debruça sobre qualquer tipo de trabalho jornalístico de meio ambiente (jornalismo ambiental ou de meio ambiente), buscando contribuir para novas formas de fazer jornalismo e fomentar a reflexão da sociedade. Isso se deve à necessidade de monitorar não apenas as atividades que podem ser nomeadas como pertencentes ao JA, ainda escassas no contexto brasileiro, mas dar conta da cobertura de questões ambientais em vários veículos de comunicação.

De forma resumida, gostaríamos de trazer três críticas que foram feitas nesse projeto a fim de explicitar que tipos de atividades se realiza e mostrar a pluralidade de pautas que são analisadas. As publicações ocorrem semanalmente, mas há possibilidade de edições extras, a depender da repercussão do acontecimento em discussão. Nossa intenção é mostrar de forma elucidativa para qual direção caminhamos com os nossos esforços de avançar com a disseminação dos pressupostos do JA e com a expansão de uma cidadania ambiental.

O primeiro artigo selecionado se chama "A explosão em Beirute e as verdades que o jornalismo insiste em não contar" (SCHILLING, 2020), publicado em 10 de agosto, sobre a explosão no depósito de Beirute, capital do Líbano. Após o mistério gerado pelas imagens que chocaram pela magnitude do fenômeno, descobriu-se que a explosão ocorreu devido ao depósito de quase três mil toneladas de nitrato de amônio, base para produção de muitos fertilizantes criados após a Segunda Guerra Mundial. 0 acúmulo do material no porto da cidade representava um risco que foi ignorado, e a análise midiática baseada em notícias do Jornal Nacional revela que o debate foi superficial. Apesar do desastre ocorrido, o telejornal insistiu na "iminência da escassez de alimentos" caso agroquímicos como esse deixassem de ser utilizados, posicionando-se a favor do uso dos agrotóxicos. Não é trivial salientar que o telejornal apresentou fontes com essa posição pré-estabelecida: um engenheiro agrônomo e a Associação Nacional de Difusão do Adubo (ANDA).

Diante disso, destacam-se os pressupostos do JA, pois a solução contra a superficialidade da cobertura midiática sobre o ocorrido só pode ser encontrada em um jornalismo mais "alargado" que contemple uma pluralidade de vozes. Em outras palavras, deve-se ampliar a visão da cobertura no sentido de ouvir diferentes narrativas como as das pessoas afetadas pela produção de fertilizantes, dos(as) estudiosos(as) em agroecologia, dos(as) pesquisadores(as) que se dedicam à historicidade dos agrotóxicos, entre outras vozes que podem ser importantes à cobertura do fenômeno. 
A segunda crítica, "Quando o Brasil vai entender que sem os povos indígenas nós não vamos constituir uma nação?" (FANTE, 2020), foi publicada em 15 de junho de 2020, a partir de uma fala de Ailton Krenak, pensador indígena brasileiro. Krenak afirma que a comunicação social hegemônica manteve a invisibilidade dos povos originários do Brasil mesmo após o início do período democrático, persistindo até os dias atuais. Os graves problemas de genocídio e, consequentemente, de ecocídio que se relacionam com os povos da floresta ainda são pouco pautados, apesar de sua importância.

Além de dar foco a um grupo social que é historicamente silenciado pela imprensa, a crítica evidencia a expansão dos meios como forma de democratização da comunicação, assinalando como a internet e as mídias sociais têm desempenhado um papel fundamental na veiculação de mobilizações relevantes em torno dos povos originários e sua sobrevivência. Como exemplo, há a menção da comunicação de uma campanha em prol dos Guarani Mbya da Retomada Indígena de Maquiné (RS) diante da negligência dos órgãos públicos frente ao alastramento da pandemia da covid-19 no estado.

A repercussão do problema nas emissoras hegemônicas só ocorreu no início da pandemia, quando órgãos públicos ligados à questão indígena realizaram uma entrega de recursos ao grupo que mantém sua retomada apesar da crise sanitária. Por isso, a crítica à invisibilidade se refere também à predileção pelo que se considera como "fontes oficiais" em detrimento das pessoas que vivenciam os conflitos socioambientais, como os povos indígenas.

É preciso lembrar que, além do fato de as pessoas envolvidas no conflito terem informações muito mais densas sobre os fenômenos devido a sua vivência cotidiana, existe a difícil dimensão do diálogo intercultural, que é negado quando se ouve apenas uma perspectiva (a hegemônica). Ao valorizar a visão sistêmica, o JA busca abarcar uma multiplicidade de vozes a fim de trazer os entendimentos, os interesses, as contradições e os conflitos da forma mais completa possível.

Já a crítica "A materialização das queimadas na economia: o jornalismo diante do boicote aos produtos brasileiros" (BEZERRA, 2019), publicada em 23 de setembro de 2019, aborda como a imprensa nacional tem debatido firmemente a questão ambiental catastrófica das queimadas na maior floresta do país através da questão econômica, já que a visão negativa da comunidade internacional em relação ao Brasil tem causado suspensão de compras da indústria do país. 
A crítica mostra a forte conexão entre economia e meio ambiente quando prejuízos financeiros estão em jogo. A partir da análise de uma matéria do El Pais (que alerta sobre o perigo de investimentos serem suspensos caso não haja uma devida responsabilidade socioambiental para com os envolvidos na catástrofe que afeta o mundo inteiro) e de notícias d'O Globo e Correio Braziliense (que enfatizam a postura de negação de Bolsonaro em relação às suspensões de compras), discute-se como o fator econômico pode forçar a ampliação da abordagem ambiental, permitindo a conexão entre diferentes setores e assuntos (BRÊTAS et al., 2019; MENDONÇA, 2019; SOARES, 2019).

As questões ambientais são complexas e transversais e demandam esforços de todas as editorias. Embora as lentes da economia não sejam suficientes para entender o processo de exploração da natureza, ela também precisa ser explicitada. Pelo viés das relações internacionais e econômicas, pode-se entender que a fumaça de uma queimada pode se dissipar para longe dos nossos olhos, impactando a economia de todo país e, consequentemente, a de nossa realidade mais próxima. Logo, a cobertura jornalística de meio ambiente precisa considerar as várias partes e enfoques dos acontecimentos, sendo as bases do JA indicativos de como qualificar a informação sobre meio ambiente e, consequentemente, respaldar de forma consistente as ações dos cidadãos.

\section{Considerações finais}

Entendendo que a questão ambiental não é banal e se desdobra direta ou indiretamente em todas as esferas sociais e âmbitos da nossa vida, percebe-se que as críticas sobre o tema apresentam limites decorrentes da própria lógica de produção jornalística, que fragmenta e setoriza os temas para dar conta dos principais acontecimentos do dia. Assim, do ponto de vista de cada editoria, certas visões e enquadramentos são privilegiados. Como são poucos os veículos que apresentam diariamente um espaço dedicado às pautas ambientais, as bases do JA são encontradas de maneira parcial e esporádica. 0 jornalismo ambiental empírico apresenta lacunas, mas a promoção de sua compreensão conceitual contribui para que outros modos de perceber a realidade sejam, aos poucos, inseridos nas representações da imprensa.

Enquanto o jornalismo não incorporar a defesa ambiental, a apresentação de como os temas podem ser melhor cobertos, proposta pelo OJA, constitui-se em um apontamento de 
que há grupos sendo invisibilizados, alternativas sendo ocultadas, interesses hegemônicos sendo comparados ao interesse comum, ao interesse público.

Os observatórios de mídia, tal como o OJA, atestam as potencialidades pedagógicas do jornalismo ambiental, pois suscitam questionamentos acerca das práticas fragmentárias e reivindicam percursos mais reflexivos e atentos aos compromissos sociais e democráticos necessários ao jornalismo. Representam ainda a tentativa de compartilhar com a sociedade uma leitura crítica sobre a condução dessa prática.

A crítica jornalística ambiental, no entanto, defronta uma regularidade dos fazeres, ocasionada por critérios de noticiabilidade que refletem uma lógica estruturada sob a temporalidade do agora (do tempo imediato), que, por sua vez, remonta à ausência de enquadramentos sistêmicos no regime noticioso. Também o destaque à excepcionalidade dos acontecimentos priva o jornalismo de quadros mais complexos, prejudicando uma crítica midiática com padrões de monitoramento e ética mais exitosos. A própria lógica do jornalismo é contestada, na medida em que afeta seu papel social de servir ao interesse público.

Como exposto no texto, o desenvolvimento do OJA ocorreu em um grupo de pesquisa dentro de uma universidade pública. Assim, gostaríamos de concluir sublinhando a importância do desenvolvimento de projetos de extensão nas áreas de pós-graduação em Comunicação que contribuam com a crítica de mídia no Brasil. Percebemos que o pioneirismo do OJA na crítica do jornalismo ambiental ocorreu principalmente por causa da concentração de pesquisadores que estudam continuamente as inter-relações e dilemas entre a Comunicação e as questões ambientais contemporâneas. Assim, a delimitação e consecução do projeto de extensão se baseou tanto nas pesquisas individuais de dissertação de mestrado e tese de doutorado, como também nas pesquisas sobre a epistemologia do jornalismo ambiental, desenvolvidas de forma coletiva.

Contudo, projetos de extensão dessa natureza, que consigam, de fato, influenciar os profissionais da imprensa ou a mesma a opinião pública demandam uma série de esforços, pontuados por Motta (2008), que vão além da criação de um espaço digital. A vigilância sobre a qualidade dos conteúdos e um planejamento consistente são alguns dos desafios, que devem levar em conta ainda os períodos de inatividade da universidade, a constante substituição de estudantes, o distanciamento com o mercado de trabalho e a escassez de recursos. 
Tais questões apontam para barreiras na manutenção de projetos de longo prazo no âmbito da academia, muitas vezes difíceis de manter, mas necessários para uma mudança cultural efetiva.

\section{Financiamento}

O presente trabalho foi realizado com apoio da Coordenação de Aperfeiçoamento de Pessoal de Nível Superior - Brasil (CAPES) - Código de Financiamento 001.

\section{Agradecimentos}

À professora Ilza Girardi, coordenadora do Grupo de Pesquisa Jornalismo Ambiental e do Observatório de Jornalismo Ambiental, e a todos os colegas que colaboram para a difusão de um jornalismo mais crítico e alinhado com a sustentabilidade da vida.

\section{Referências}

ALBORNOZ, Luís; HERSCHMANN, Micael. Os observatórios ibero-americanos de informação, comunicação e cultura: balanço de uma breve trajetória. E-Compós, [S. l.], v. 7, 2006.

BELMONTE, Roberto Villar. Uma breve história do jornalismo ambiental brasileiro. Revista Brasileira de História da Mídia, [s. l.], v. 6, n. 2, p. 110-125, 2017.

BEZERRA, Eutalita. A materialização das queimadas na economia: o jornalismo diante do boicote aos produtos brasileiros. Observatório de Jornalismo Ambiental, Porto Alegre. 2019.

BRÊTAS, Pollyanna; MARTINS, Gabriel; SCHMITT, Gustavo; OSWALD, Vivian. Com crise em torno da Amazônia, cresce temor de boicote a produto brasileiro. O Globo, Rio de Janeiro, 26 de agosto de 2019.

BRUM, Eliane. Brasil, construtor de ruínas - Um olhar sobre o país, de Lula a Bolsonaro. Porto Alegre: Arquipélago Editorial, 2019.

BUENO, Wilson. Comunicação, jornalismo e meio ambiente: teoria e pesquisa. São Paulo: Majoara, 2007.

CUNHA, Patrícia. Observatórios de mídia: conceitos, práticas e fundamentos. Dissertação (Mestrado em Comunicação) - Programa de Pós-Graduação em Comunicação, Universidade Federal de Pernambuco, Recife, 2011.

DAMAS, Susana Herrera; CHRISTOFOLETTI, Rogério. Mídia e democracia: um perfil dos observatórios de meios na América Latina. Unirevista, [s. l.], v. 1, n. 3, p. 1-11, jul. 2006. 
FANTE, Eliege. "Quando o Brasil vai entender que sem os povos indígenas nós não vamos constituir uma nação?". Observatório de Jornalismo Ambiental, Porto Alegre, 15 de jun. 2020 .

FENAJ. Código de Ética dos Jornalistas Brasileiros. Vitória: FENAJ, 2007.

FREIRE-BEZERRA, Juliana. 0 diálogo potente no jornalismo: pensando a interatividade em seu viés pedagógico. RAEIC, [s. l.], v. 7, n. 13, p. 99-117, fev. 2020.

FROME, Michael. Green Ink - Uma Introdução ao Jornalismo Ambiental. Curitiba: Editora da UFPR, 2008.

GADOTTI, Moacir. Pedagogia da terra. São Paulo: Petrópolis, 2000.

GAVIRATI, Pablo. Mediatizar el ambiente, ambientalizar los médios: tensiones en torno al discurso periodístico sobre el cambio climático. In: FERNÁNDEZ-REYES, Rogelio; MANCINASCHÁVEZ, Rosalba (Coords.). Actas de las Jornadas Internacionales Medios de Comunicación y Cambio Climático. Sevilla: Fénix editora, 2013. p. 217-232.

GIRARDI, Ilza Maria Tourinho. Um semestre muito especial: o surgimento da primeira disciplina de jornalismo ambiental. In: GIRARDI, Ilza Maria Tourinho; MORAES, Cláudia Herte De; LOOSE, Eloisa Beling; BELMONTE, Roberto Villar (orgs.). Jornalismo Ambiental: teoria e prática. Porto Alegre: Metamorfose, 2018. p. 13-24.

LEFF, Enrique. A aposta pela vida: Imaginação sociológica e imaginários sociais nos territórios ambientais do Sul. Petrópolis: Vozes, 2016.

MENDONÇA, Heloísa. Boicote por crise dos incêndios na Amazônia chega ao mercado financeiro e acende alerta. El País, 31 ago. 2019.

MORAES, Fabiana. Subjetividade: Ferramenta para um jornalismo mais íntegro e integral. Extraprensa, São Paulo, v. 12, n. 2, p. 204-219, 2019.

MOREIRA, Douglas Silva. Observatórios de mídia: contribuições para a proteção de direitos humanos nos meios de comunicação. Dissertação (Mestrado em Comunicação) Universidade Federal do Paraná, Curitiba, 2013.

MORIN, Edgar; CIURANA, Emilio Roger; MOTTA, Raúl Domingo. Educar para a era planetária: o pensamento complexo como método de aprendizagem no erro e na incerteza humana. São Paulo: Editora Cortez, 2003.

MOTTA, Luiz Gonzaga. Crítica da mídia: Da resistência civil ao desenvolvimento humano. In: CHRISTOFOLETTI, Rogério; MOTTA, Luiz Gonzaga (orgs.). Observatórios de mídia: Olhares da cidadania. São Paulo: Paulus, 2008. p. 19-38.

PROREXT UFRGS. 0 que é Extensão? Rio Grande do Sul: Pró-Reitoria de Extensão da UFRGS, 2021. 
REBOUÇAS, Edgard; CUNHA, Patrícia. Observatórios de mídia como instrumentos para (da) democracia. Reciis, Rio de Janeiro, v. 4, n. 4, p. 85-93, nov. 2010.

RENOI. Censo 2021 RENOI - Rede Nacional de Observatórios de Imprensa. Brasília-DF, 2021.

ROCHA NETO, Manoel Pereira; BARRETO, Laís Karla da Silva; CARVALHO, Isabel Cristine Machado de; MORAIS, Gabriel Rodrigues. A contribuição do Observatório da Imprensa como instrumento da crítica de mídia no Brasil. Revista Observatório, Palmas, v. 1, n. 3, p. 201220, dez. 2015.

SÁ CORREIA, Marcos. Apresentação. In: FROME, Michael. Green Ink - Uma Introdução ao Jornalismo Ambiental. Curitiba: Editora da UFPR, 2008. p. 27-32.

SCHILLING, Ursula. A explosão em Beirute e as verdades que o jornalismo insiste em não contar. Observatório de Jornalismo Ambiental, Porto Alegre. 8 de out. 2020.

SILVA, Gislene da; SOARES, Rosana de Lima. Para pensar a crítica de mídias. Revista Famecos, Porto Alegre, v. 20, n. 3, p. 820-839, set./dez. 2013.

SOARES, Ingrid. Bolsonaro nega boicote a couro brasileiro por conta da Amazônia. Correio Braziliense, Distrito Federal, 28 de ago. 2019.

SOARES, Rosana de Lima; SILVA, Gislene da. Lugares da crítica na cultura midiática. Comunicação, mídia e consumo, São Paulo, v. 13, n. 37, p. 9-28, maio/ago. 2016.

STENGERS, Isabelle. No tempo das catástrofes: resistir à barbárie que se aproxima. São Paulo: Cosac Naify, 2015.

SWAMPA, Maristella. As fronteiras do neoextrativismo na América Latina: Conflitos socioambientais, giro ecoterritorial e novas dependências. São Paulo: Elefante, 2019.

TÉLLEZ, Maria Patrícia. Observatório e ouvidorias: experiências de crítica midiática e cidadania na América Latina. Tese (Doutorado em Comunicação e Informação) Universidade Federal do Rio Grande do Sul, Porto Alegre, 2011.

\title{
Observatory of Environmental Journalism: an extension project in favor of citizenship
}

\begin{abstract}
Media observatories can be seen as political actors who show resistance, reminding audiences of the social role of journalism and showing critical ways of seeing events. Based on this understanding, the Environmental Journalism Research Group (GPJA), from the Federal University of Rio Grande do Sul (UFRGS) presents that the creation of an observatory dedicated to environmental coverage could not only expand knowledge
\end{abstract}


beyond the walls of the university, taking academic reflections to other spaces and actually practicing extension from teaching and research activities, but qualify the environmental debate in the brazilian context, fostering the effective exercise of planetary citizenship. This text, with an exploratory analytical character, presents an initiative and discusses the challenges associated with environmental journalistic criticism. As final considerations, the limits identified in empirical production are highlighted, arising from a journalistic logic not always associated with citizenship, and in the maintenance of extension projects in universities, factors that restrict the pedagogical potential of observatories and, in this case, of the debate on environmental journalism.

\section{Keywords}

Media Observatory; Environmental Journalism; Journalistic Criticism; Extension; Journalism and Citizenship

\section{Autoria para correspondência}

Nome Eloisa Beling Loose

E-mail eloisa.beling@gmail.com

\section{Como citar}

LOOSE, Eloisa Beling; CERVO, Matheus; LENGERT, Mathias. Observatório de Jornalismo Ambiental: um projeto de extensão em prol da cidadania. Intexto, Porto Alegre, n. 53, e-110698, jan./dez. 2022. DOI: http://dx.doi.org/10.19132/1807-8583202253.110698

Recebido em 15/01/2021

Aceito em 14/10/2021 